\title{
Experimental Investigation on Hybrid Propulsion Technology to Increase Fuel Efficiency and Reduce Carbon Emission
}

\author{
${ }^{1}$ Dr. R. Rajendran, ${ }^{2}$ Priya Darshini.S, ${ }^{3}$ Sanjay.N, ${ }^{4}$ Sanjay. S, ${ }^{5}$ Sujith. T, \\ ${ }^{1}$ Professor, Department of Aeronautical Engineering, Dayananda Sagar College of Engineering, Bengaluru, India. \\ ${ }^{2,3,4,5}$ Student, Department of Aeronautical Engineering, Dayananda Sagar College of Engineering, Bengaluru, India.
}

\begin{abstract}
Hybrid aircraft propulsion systems, is the combination of electrically driven fans and on-board battery storage, therecent studies show that there is more potential to reduce aircraft fuel consumption and emissions significantly. The main advantages of hybrid aircraft are fuel savings, lower carbon emissions, and reduction in noise level. Since the hybrid aircraft run on multiple power sources such as mechanical and electrical, flight sustainability can be improved in case of failure of individual parts in the propulsion system. Thus, an increase in flight safety can be another benefit of the hybrid-electric propulsion concept. The demand for non-renewable energy sources continually increases, and the energy source is exponential decreasing due to the increase in the automobiles.

This paper demonstrates the overview of hybrid electric vehicles, its construction, design, and development on a small scale using the nitro fuelled piston engine ( 2 strokes) and integrated electric motor. This project mainly aims to develop a hybrid system on a small scale and implementing it on an RC aircraft to study the performance of thrust efficiency and carbon emission. This is done by developing a system that extracts energy from the engine, stores the energy, and transfers it to the electric motor and thereby producing additional thrust.
\end{abstract}

Keywords-Carbon emission, fuel efficiency, hybrid energy, generator, propulsion.

\section{INTRODUCTION}

Hybrid electric propulsion aircraft is an electric motor integrated with the reciprocating engine (piston engine). In recent times with the emission of carbon and many more greenhouse gases, the pollution rates increase drastically, causing severe problems to the environment. Hybrid electric aircraft were found to have much more attention in recent years due to their ability to reduce the impact on the environment due to civil aviation, which contributes to the global carbon dioxide $\left(\mathrm{CO}_{2}\right)$ emissions by two percent from transport. To achieve lower carbon emission, the transition to hybrid-electric aircraft is considered as one of the essential steps. In addition to increased fuel efficiency, when compared to commercial aircraft, these aircraft would emit less noise and fewer carbon particles.

It mainly consists ofthe combination of the propulsion system, which consists of an electric motor and an IC engine. The electric motorstake in power from the onboard batteries. In a hybrid vehicle, the IC engine is combined with electric motors, which leads to more optimal use of the engine. During engine idling speed, the fuel consumption is more without producing less useful work, thus contributing to the increase in emission from the exhaustand decreased efficiency. This way, no fuel consumption was reduced during idling, which in turn reduces the exhaust emission. Another significant advantage of a hybrid vehicle is that when the fuel gets consumed fully while driving the engine, then the electric power stored drives the vehicle within the maximum range. Hybrid vehicles produce fewer emissions compared to a similarsized gasoline engine alone, the gasoline engine of the hybrid vehicles can be optimized to run at the maximum efficiency. The primary significance of electric power is that it runs with low power loss, hence thereby improving the overall fuel economy rate. Hybridization of vehicles can reduce $\mathrm{CO} 2$ emission and also the fuel costs and also increases flying range when compared with electric powered only aircraft. For these reasons, there is a significant interest in technology and the further improvement of these systems. The investigation aims to design, develop, and optimize a hybrid electric system to act as the main propulsive for the aircraft, hence minimizing the impact on environment and improving aircraft performance.

\section{CHARACTERIZATION OF HYBRID PROPULSION SYSTEMS}

In recent years the hybrid systems are emerging due to the high functional performancesand also in achieving higher efficiency, thus recently an e-genius a generator system, based on an automotive engine, is currently integrated into the aircraft, the main objective of the project is to determine the potential capability of electricallypropelled aircraft ${ }^{[1]}$. Next, a hybrid engine with validated design has been analyzed in a turboprop aircraftand is continued with analysis and sizing modules for hybridelectric propulsion system components. From the results, it is investigated thatthe performance and range for this type of aircraft are limiteddue to the battery technology level ${ }^{[2]}$. The main driving forces in considering electric propulsion for aircraft arereduced emissions along with exhaust particles and noise, but more studies have revealed thatthe energy efficiency and flexibility of modern aircraft types were done by a sky-diving mission which resulted in the better reduction of carbon emission and fuel consumption, but the mission has issues with battery and electronic components ${ }^{[3]}$. The main process of converting aircraft propulsion systems 
into the hybrid systemby the addition of electric motors and battery storage and how different hybrid-electric aircraft (HEA) operation regimes may affect the battery life of the electric storage system. Battery cycling tests were done on three widely proposed electric operation regimes -a constant power regime, a stepped power regime, and a ramped power regime- are conducted. Finally, from the results, we can infer that the stepped power operation regime was found to be best for retaining the capacity when compared to the ramped power regime of ESS batteries, as the ramped power regimedesigned to maximize fuel saving leads to quick battery degradation most severely ${ }^{[4]}$. Thus we conclude that hybrid-electric aircraft are emerging the field to maximize the performance and minimize the carbon emission as well as the fuel consumption and to keep our environment safe whereby emerging hybrid aircraft creates a new economy rate which will have a huge impact where each and every person can afford the usage of aircraft for travelling.

\section{III.HYBRID PROPULSION SET-UP}

In general, the hybrid set-up in our project refers to the mechanical systems with a combination of electronic systems, where the power generated by the piston engine is converted into electrical energy via battery management system (BMS), and the electric power obtained is required to run the external motors simultaneously. Explaining in detail that according to the hybrid propulsion system [1], many engines run on fuel-powered the fuel which we used for the piston engine is Nitro fuel commonly used for RC aircrafts applications, now starting the engine has 3 starters, hand crank, air starter and electric or push the starter. For our engine by hand cranking, we need to start the engine thereby supplying the fuel in a gravity feed manner, so that make sure that sufficient amount of fuel enters the piston head of engine for the efficient combustion process, by stating the combustion process here an additional device called Fuel booster is used for igniting the fuel for the combustion to take place, and thus sufficient power is generated. Now using a mechanical coupling such as a pulley of desired specifications connected to the engine shaft and the generator thereby the mechanical power generated from the engine is converted into electrical power this supply is initially fed to the battery management system or the power generation module which stabilizes the voltage and avoids any further fluctuations in the output, The output is sent to the power distribution board which equally distributes the power and supplies to the Electronic speed controller (ESC) which acts as the major brain part in accessing the current obtained and makes the external motors to run efficiently at the same RPM, The concept of a brushless direct-current electric motor (BLDC) is based on the electronic phase commutation.The rotor consists of permanent magnets, whereas the stator consists of electromagnetic coils. As the brushless DC motor is three-phased, coil system required for its operation, and an electronic speed controller (ESC) is mandatory. The electronic speed controller is to convert the direct-current input into an approximated sinusoidal threephase current using transistors. The elimination of the brushes reduces friction and heat dissipation.Thus the desired thrust can be generated by the piston engine, as well as the fuel consumption can be minimized which serves as an advantage in an economical manner thereby the concept of hybrid set-up when it is applied on large scale applications irrespective of disadvantages, It will create a new economy of having greater performance when compared to the presently available applications. The below block diagram shows the entire hybrid propulsion set-up connection.

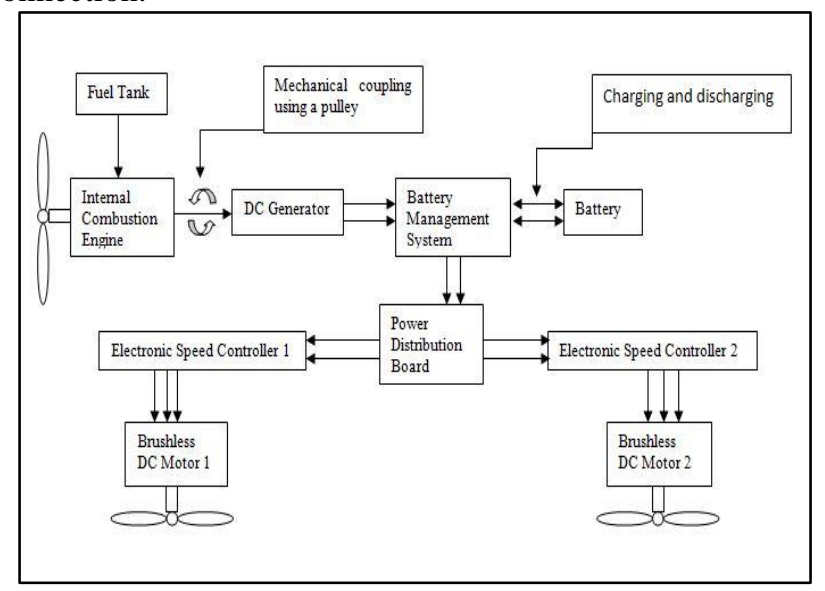

Fig.1: Block diagram of the hybrid set-up.

\section{ENGINE AND GENERATOR MODULE}

In the hybrid propulsion system, the internal combustion reciprocating piston engine which converts the chemical combustion of energy in the gasoline forminto the shaft rotational mechanical energy. We used the commercial 2 stroke ASP (S91A) piston engine which is generally used in RC aircraft applications, the rotational mechanical energy obtained from the engine shaft is converted into the electrical energy with the help of a generator. The engine shaft and generator shaft are connected via pulley and belt mechanism, thus for higher speeds, the round belts are preferred, thus minimizing the vibrations occurring from the combination of engine and generator. The generator of the hybrid-electric unit transforms mechanical energy into electric energy.

Here the generator's maximum rpm is 30,000 , but the engine's maximum rpm is 17,500 . Hence we had to make the size of the generator pulley small when compared to that of the engine pulley. This was done so that the generator spins faster than the engine and thereby matching the rpm of both engine and generator. These pulleys are connected using a rubber belt at high tension. The usage of the belt was opted as using gears for the transmission may cause a lot of wear and tear and also causes more rpm loss when compared to the belt. Thus engine and generator modules are connected in a parallel manner so that vibrations can be minimized to a great extent and avoid wear and tear of belts and can have an undisturbed RPM throughout the process.

\section{V.BATTERY MANAGEMENT SYSTEM}

Battery management system (BMS) is a device that is used for monitoring the charging and discharging cycles of rechargeable batteries.It mainly monitors vital operational parameters such as voltages, currents, and the internal temperature of a battery during charging and discharging. If any of the parameters exceed the limits, then theintegrated 
circuits would sense the exceeded parameter and would disconnect the load or the charger from the battery. The decisionson charge or discharge rates made by the BMS is based on estimated battery State Of Charge(SOC), battery capacity, impedance, voltage, current, temperature measurements, load demands, etc.The primary function of the BMS is to control the discharge of a battery, whereas its primary goal is to make sure that the battery is operating within the operational limits and thereby protect the cells during discharging and charging. Keeping track of battery SOC is one of the features of the. TheSOC could indicate the user and control the charging and discharging process. There arethree methods of determining SOC: through direct measurement, through coulomb from a single measurement of either the cell impedance or the cell conductance.

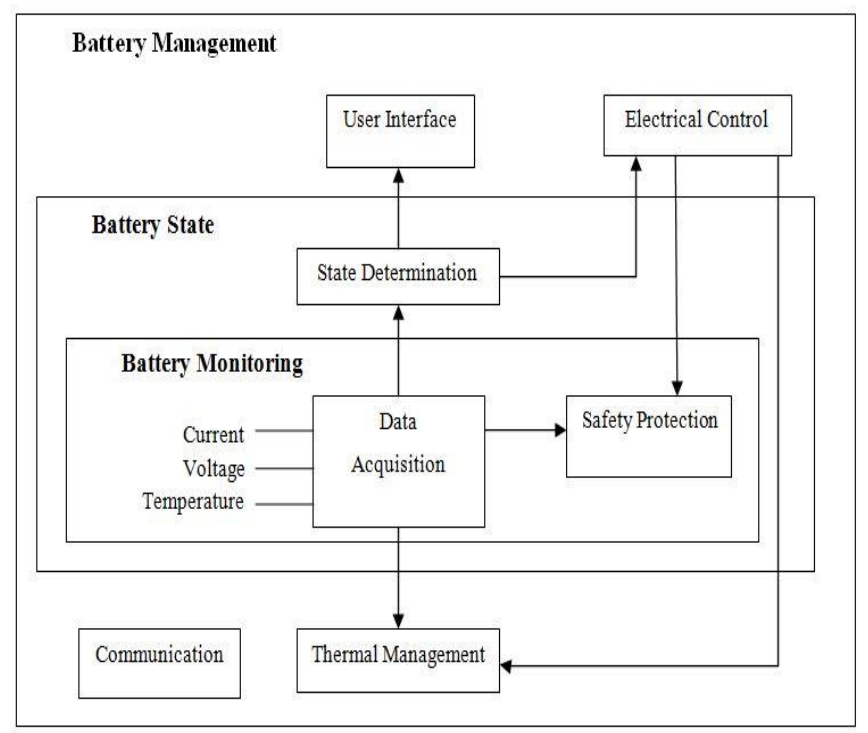

Fig.2: Block diagram of a Battery Management System.

\section{VI.RESEARCH METHODOLOGY}

\section{A. Hybrid set-up integrated in a UAV}

Initially in the hybrid propulsion system, the major part is the design where we need to survey on each and every component specifications and makes sure that they are placed in such a manner of producing the higher level performance and desired thrust with optimum strength to weight ratio, thus a UAV model consisting the components are placed in the series and parallel combination based on their power losses, and we need to make sure that there must be minimum power loss to maximize the efficiency needed.

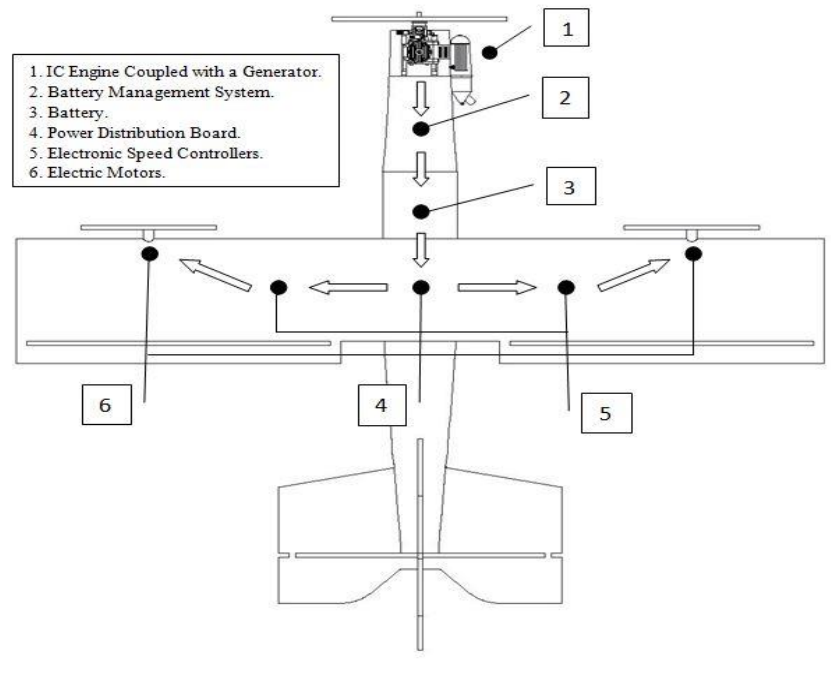

Fig.3: The hybrid set-up integrated into a UAV.

From the above block diagram, the specifications of the components can be given in the table below:

TABLE.1: The components used along with their specifications.

\begin{tabular}{|c|c|c|c|c|}
\hline $\begin{array}{c}\text { Internal } \\
\text { Combustion } \\
\text { Engine }\end{array}$ & $\begin{array}{l}\text { Asp piston } \\
\text { engine } \\
\text { S91A }\end{array}$ & $\begin{array}{l}\text { Output } \\
2.20 \mathrm{kw}\end{array}$ & $\begin{array}{c}\text { Practical } \\
\text { RPM } \\
2000- \\
17500\end{array}$ & $\begin{array}{c}\text { Displace } \\
\text { ment } \\
14.93 \mathrm{cc}\end{array}$ \\
\hline Engine Propeller & $\begin{array}{c}\text { Diameter: } \\
33 \mathrm{~cm}\end{array}$ & $\begin{array}{l}\text { Pitch: } \\
12.7 \mathrm{~cm}\end{array}$ & & \\
\hline Motor propeller & $\begin{array}{l}\text { Diameter: } \\
25.4 \mathrm{~cm}\end{array}$ & $\begin{array}{c}\text { Pitch: } \\
11.43 \mathrm{~cm}\end{array}$ & & \\
\hline Dc generator & $\begin{array}{c}\text { Output } \\
\text { voltage:0- } \\
24 \mathrm{v} \\
\end{array}$ & $\begin{array}{c}\text { Output } \\
\text { current:0- } \\
2 \mathrm{Amps} \\
\end{array}$ & $\begin{array}{l}\text { RPM: } \\
30000\end{array}$ & \\
\hline Electric Motor & $\begin{array}{l}\text { Output:140 } \\
\text { 0(RPM/V) }\end{array}$ & $\begin{array}{c}\text { Current } \\
\text { capacity: } \\
16 \mathrm{~A} / 60 \mathrm{~s}\end{array}$ & & \\
\hline Battery & Lithium-ion & $\begin{array}{c}\text { Output } \\
\text { voltage: } 1 \\
2 \mathrm{~V} \\
\end{array}$ & $\begin{array}{l}\text { Capacity: } \\
\text { 2200mAH }\end{array}$ & \\
\hline $\begin{array}{l}\text { Electronic Speed } \\
\text { Controllers }\end{array}$ & 3-phase & $\begin{array}{c}\text { Input } \\
\text { voltage: } \\
6-12 \mathrm{~V}\end{array}$ & $\begin{array}{c}\text { Constant } \\
\text { current:30A }\end{array}$ & \\
\hline
\end{tabular}

\section{B. Formulas and calculations}

The thrust produced by the whole hybrid set-up was calculated as this will give a proper insight into whether this set-up is efficient for the extra weight added. In order to determine the thrust produced, the RPM of the engine is necessary for different throttle positions. The RPM was found out using a digital tachometer, and the following results were noted down.

TABLE.2: RPM values for respective throttle positions.

\begin{tabular}{|c|c|}
\hline Engine Throttle Position & Engine RPM \\
\hline Minimum throttle & 10239 \\
\hline Half throttle & 14639 \\
\hline Full throttle & 17142 \\
\hline
\end{tabular}

Using the above RPM values, the static thrust produced by the engine was found out using the formula: 


$$
\begin{aligned}
& \text { Expanded Form: } \\
& \qquad \begin{array}{r}
F=1.225 \frac{\pi(0.0254 \cdot d)^{2}}{4}\left[\left(R P M_{\text {prop }} \cdot 0.0254 \cdot \text { pitch } \cdot \frac{1 \mathrm{~min}}{60 \mathrm{sec}}\right)^{2}\right. \\
\left.-\left(R P M_{\text {prop }} \cdot 0.0254 \cdot \text { pitch } \cdot \frac{1 \mathrm{~min}}{60 \mathrm{sec}}\right) V_{0}\right]\left(\frac{d}{3.29546 \cdot \text { pitch }}\right)^{1.5}
\end{array}
\end{aligned}
$$

Simplified Form:

$$
F=4.392399 \times 10^{-8} \cdot R P M \frac{d^{3.5}}{\sqrt{p i t c h}}\left(4.23333 \times 10^{-4} \cdot R P M \cdot p i t c h-V_{0}\right)
$$

Fig.4: Static thrust equation.

From the above equation $\mathrm{v}_{\mathrm{o}}$ (airspeed)is taken as zero for static thrust calculation, and the thrust is measured in Newton, RPM is the Rotations Per Minute of the propeller. Where ' $\mathrm{d}$ ' is the diameter of the propeller in "inches," Pitch is the propeller pitch for the chosen propeller in "inches."

Using the above equation, the static thrust produced by the engine was found out to be:

TABLE.3: The thrust produced for respective throttle position.

\begin{tabular}{|c|c|}
\hline Engine Throttle Position & Thrust Produced \\
\hline Minimum throttle & $31.9 \mathrm{~N}(3.25 \mathrm{kgf})$ \\
\hline Half throttle & $71.71 \mathrm{~N}(7.31 \mathrm{kgf})$ \\
\hline Full throttle & $97.71 \mathrm{~N}(9.96 \mathrm{kgf})$ \\
\hline
\end{tabular}

The above formula was also used to find the static thrust produced by the electric motors. The RPM of the electric motors can be calculated by: $(\mathrm{kV}$ rating of the motor) *(Battery voltage). Hence the static thrust was found to be $58.86 \mathrm{~N}(6 \mathrm{kgf})$ for the two electric motors. Hence from these calculations, we can infer that a combined total thrust of $10 \mathrm{kgf}$ and above is obtained, which is more than required in order to compensate for the extra weight added into the setup.

Flight time calculation:

Now we'll find the time the battery takes to run the electric motors until discharge, and this time can be considered as the flight time for that battery. Here we are using a lithiumion (Li-ion) battery having $2200 \mathrm{mAH}$ capacity and $12 \mathrm{~V}$.

$2200 \mathrm{mAH}=2.2 \mathrm{~A}$ for $1 \mathrm{Hr}$.

The max amps of electric motor $=8 \mathrm{~A}$.

As the effective capacity for a Li-ion battery is around $78 \%$ (one shouldn't discharge a battery more than $78 \%$ ), the total capacity of the battery becomes $=2.2 * 0.78=1.716 \mathrm{~A}$ for $1 \mathrm{Hr}$.

The flight time is given by:

Flight time $=($ Battery Amps/Motor Amps $) * 60$ in minutes. Hence for our battery, it was found to be 12.87 or 13 minutes. This means that our battery can run the electric motors for a period of 13 minutes at full throttle.

\section{VII.EXPERIMENTAL ANALYSIS AND STATISTICS}

The set-up is now assembled and is tested in order to evaluate whether the output produced is capable of running the electric motors. The output voltage and current were recorded, and the power output was calculated. The values are as shown in the table below.

TABLE.4: Power output for respective throttle positions.

\begin{tabular}{|c|c|c|c|}
\hline $\begin{array}{c}\text { Engine } \\
\text { Throttle } \\
\text { Position }\end{array}$ & $\begin{array}{c}\text { Output } \\
\text { Voltage (V) }\end{array}$ & $\begin{array}{c}\text { Output } \\
\text { Current (A) }\end{array}$ & $\begin{array}{c}\text { Power Output } \\
\left(\mathbf{V}^{*} \mathbf{I}\right)\end{array}$ \\
\hline $\begin{array}{c}\text { Minimum } \\
\text { throttle }\end{array}$ & 12 & 5 & 60 \\
\hline Half throttle & 16 & 6 & 96 \\
\hline Full throttle & 20 & 8 & 160 \\
\hline
\end{tabular}

Here the output voltage is measured in "Volts," output current in "Amperes" and power output in "Watts." A graph showing the power output for respective engine RPM is plotted below.

\section{POWER VS RPM}

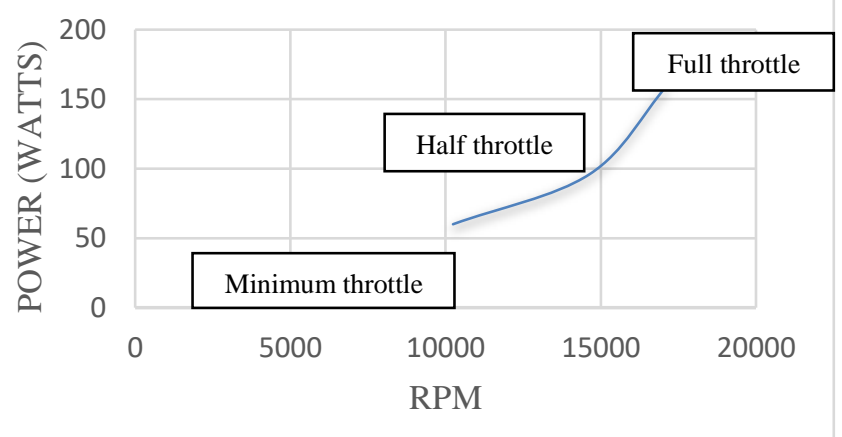

Fig-5: Graph of power output vs engine RPM.

Thus, from the experimental analysis, we can infer that the obtained power is more than sufficient in order to run the electric motors. Further, since the engine running at low throttle produces the necessary power to run the electric motors, its fuel consumption and the carbon emission level will be minimum when compared to fuel-powered airplanes, and the endurance can be obtained for about 1-2 hours when compared to that of an electric-powered airplane.

\section{VIII.CONCLUSION}

This project aims to create a hybrid system that can be implemented on an aircraft for better fuel efficiency and reduced emission. In this case, the IC engine is used to generate the power required for the motors, and hence the thrust is produced from both the IC engine as well as electric motors. This increases the efficiency of the fuel used, and also, we can reduce fuel consumption, thereby reducing the emission. The set-up can be automated using integrated and programmable electronic components in order to effectively monitor the outcome. The set-up can be modified to improve the performance using HIL testing (Hybrid test rig). A more advanced generator that is lightweight and produces the necessary power can be used. The engine throttle control can be fully automated so that a constant RPM is produced, thereby reducing the fluctuations in the output. This set-up can be converted into a fully functional hybrid UAV whose endurance is much higher than the conventional electric UAVs. 


\section{REFERENCES}

[1] Stefan Notter and Walter Fichter, "Optimized Operation Strategies for Serial Hybrid-Electric Aircraft," 2018.

[2] Mark Voskuijl, Joris van Bogaert, "Analysis and design of hybrid electric regional turboprop aircraft" 2017.

[3] Richard Glasswork, Michael Galea, Waren Williams, Tibor glesk, "Hybrid electric propulsion systems for skydiving aircraft," August 18, 2017, Institute for Aerospace Technology, The University of Nottingham.

[4] Qingweizhu, Andrew Forsyth, Rebecca Todd, "Investigation of Hybrid Electric Aircraft Operation on Battery Degradation," IEEE International Conference 2018

[5] Ye Xie, Al savvaris, Antonio's Tsourdos, Jason Laycock, Andrew Farmer, School of Aerospace, Transport and Manufacturing, IEEE Aerospace Conference, March 3, 2018.
[6] Subha-reddy, "Internal combustion reciprocating piston engine," University of Academia.

[7] Yinjiao Xing, Eden W. M. Ma, Kwok L. Tsui, and Michael Pecht, "Battery Management Systems in Electric and Hybrid Vehicles," City University of Hong Kong, 2015.

[8] Joachim Schömann, "Hybrid-Electric Propulsion Systems for Small Unmanned Aircraft," Technical University of Munich, Germany, 2013

[9] Hyuk RokGwon, Woo Bee Kim, Ki Woong Lee, Dae Won Kim, Hyeon Seok Lee, "Development Of Hybrid Gasoline-Battery Propulsion System For Multi-Copter Platform," Korean Air R\&D Center, 2018.

[10] Bc. ŠtepánRiss, "Development of a Hybrid Power Unit for Unmanned Aerial Vehicles," Czech Technical University in Prague, 2017 